\title{
Pedagogical Infrastructures of Design Studio Learning
}

\section{Seitamaa-Hakkarainen, Pirita}

2017-05-24

Seitamaa-Hakkarainen , P , Härkki , T , Lahti , H \& Hakkarainen, K 2017 , ' Pedagogical Infrastructures of Design Studio Learning ' , Journal of textile design, research and practice, vol. 4 (2016) , no. 2 , pp. 155-181 . https://doi.org/10.1080/20511787.2016.1325579

http://hdl.handle.net/10138/308634

https://doi.org/10.1080/20511787.2016.1325579

submittedVersion

Downloaded from Helda, University of Helsinki institutional repository.

This is an electronic reprint of the original article.

This reprint may differ from the original in pagination and typographic detail.

Please cite the original version. 


\title{
Pedagogical Infrastructures of Design Studio Learning
}

\author{
Seitamaa-Hakkarainen, P., Härkki, T., Lahti, H., \& Hakkarainen, K.
}

\begin{abstract}
In the design studio, within educational contexts, sketching, model-making and prototyping of tangible objects are parts of the design process that support students in achieving final design solutions. This paper presents research in which three design experiments involving design studio settings, using a Learning by Collaborative Designing model for supporting knowledge-creating learning for university-level craft teacher education, were undertaken. The design studios aimed at guiding first-year students to appropriate professional processes and practices of design. The Pedagogical Infrastructure Framework was applied to analyse the social, epistemic, cognitive and material-technical aspects of three design-studio settings. Through meta-analysis of the three experiments we asked: What can we learn from these design studio experiments about the pedagogical infrastructure that supports creative design practices of working with design knowledge, tools and technologies in a real learning setting? As a result of the experiments we discuss the limitations and opportunities of these pedagogical settings, as well as considerations for future development of studio-based settings as pedagogic innovations emerging for integrating material-technical and socio-digital technologies, practices and spaces for learning.
\end{abstract}

Keywords: Knowledge-creating learning, design-studio setting, collaboration, textile designing

\section{Introduction}

The purpose of this article is to analyse collaborative design studios whose objective is to guide students to appropriate professional processes and practices of design. The kind of pedagogical infrastructures and scaffolds needed, in these studios, by novice designers, in this case universitylevel first-year textile teacher students, will be addressed. The process of designing and making textiles is a complex, multifaceted activity that requires sophisticated professional thinking, domain-specific knowledge and procedural skills (Seitamaa-Hakkarainen and Hakkarainen 2001). Subsequently textile design is a creative activity and learning to design professionally requires knowledge about the social practices and working methods that are essential for creative work. The aim of the study presented is to highlight, for design educators, the essential underlying pedagogical conditions that need to be designed and addressed in the learning environment to enhance the design students' desired collaborative design practices. In design studios the pedagogical organization, the nature of design tasks and social setting are planned to enable development of students' collaborative designing skills and their understanding of multifaceted design processes. We consider collaborative designing as a prototypical example of knowledge-creation learning that goes beyond mere knowledge acquisition or social participation; it involves "trialogical" efforts of advancing shared epistemic objects (Paavola and Hakkarainen 2014) in terms of externalization of design ideas and constructing various types of tangible artefacts. Thus, research into students' 
collaborative design in studio settings helps design educators understand how to develop their pedagogies and educational methods for teaching the design and making processes.

Teaching creative practices in the design disciplines is most often based on a studio model that usually emphasizes pursuit of challenging knowledge-creation projects and emphasises learning by doing (Sawyer 2012). Traditionally, the studio is as much a place for designing as it is an instructional method: it provides an environment imitating the professional designer's work place with plentiful materials and representations (Goldschmidt, Hochman and Dafni 2010). Studiobased projects can be open-ended tasks that emphasise students' own artistic expression around given themes or can be open-ended with more pre-defined collaborative design projects. The purpose of studio-based learning is to provide students with the competencies to deal with the entire design process. In accordance with authentic professional contexts, students are introduced into the process of working with open-ended but focused design projects meeting external, design constraints determined by a design brief (Chamorro-Koc, Scott and Coombs 2015, Lee 2009, Sawyer 2012). Further, as the overall demand for collaboration between professionals has rapidly increased, individual student work has often been accompanied by co-operative and collaborative design work. Although educational projects do not involve all the constraints of real-life projects, it is critical that students learn to understand the complexity of collaborative design work, such as communicating initially fuzzy thoughts and challenges involved in transforming ideas into tangible objects.

In this paper, we present our findings from three collaborative design courses conducted with firstyear university-level students in training to become textile teachers i.e., craft teachers. In Finland, as well in other Scandinavian countries, craft education (consisting of textile and technical work) is a compulsory school subject in elementary level (grade 1 to 6 , ages 7 to 12) and at the lower secondary level, grade 7 . In grade 8 to 9 (ages 14 to 16), students can select craft education as an optional subject. In craft education, multi-materiality is emphasized and designing and craft making is seen as an exploratory, inventive and experimental activity. When designing, various textile techniques are used to materialize students own design ideas; this is focused on both creating and manipulating textile surfaces but also constructing fabric products (for example, clothes and toys).

Craft teacher education in Finland consists of five years of university studies and all qualified craft teachers must hold a Master of Arts in Education degree. The subject studies include various textile techniques (for example knitting, sewing and embroidery), clothing design and pattern making, as well as different methods for textile surface designing (dyeing, textile printing, felting and 
weaving). These studies embrace various aspects of textile designing: ideation and visualization of ideas, exploration and experimenting with materials in order to create textile surfaces, as well as constructing and making final fabric products. The studies also cover how to teach designing and making, and student teachers have several periods of practice in training schools. Moreover, the studies also emphasize digital technologies and digital documentation (for example, use of eportfolios and various digital inspirational sources), as well as use of different digital textile technologies and applications (i.e. computer supported weaving, software applications for embroidery), while designing and making.

Although textile teachers do not usually become professional designers, their future job description involves teaching collaborative design and making of craft; they have to be able to teach corresponding skills and practices in comprehensive schools and in various adult-learning settings. Textile teacher students need to learn to express design ideas and to transform ideas into physical representations and artefacts. A previous study (Laamanen and Seitamaa-Hakkarainen 2014) indicated that textile teacher students have some difficulties related to creative design processes, such as expressing design concepts and cyclically developing various design ideas in different modalities and materials, instead they can get fixed on the first plausible idea. The emergent aspects of creative thinking need to be supported by providing a collaborative environment to share and develop ideas together as well as encouraging the students to learn to nourish their collaborative design process with experimenting and trying out several ideas with materials. Thus, the design educators need to be aware of how pre-defined design tasks, tools and materials affect designing and how the organized physical and social settings support or hinder the teams' creative collaboration.

In order to address challenges in designing, we will examine the pedagogical implications of design-studio learning of collaborative practices. Our meta-analysis of three different design studio settings focuses on pedagogical infrastructures (Lakkala et al. 2008, Lakkala et al. 2010). Pedagogical infrastructures consist of the epistemic aspects of design tasks, social organization of learning settings as well as the tools and materials available. In this paper, firstly we describe the pedagogical model of learning by collaborative designing (LCD) that has informed our work. Secondly, the salient pedagogical infrastructure framework (Lakkala et al. 2008, Lakkala et al. 2010) is presented. Next, we utilize the pedagogical infrastructure framework to analyse the three design-studio contexts' associated learning activities and the tasks, tools and materials given to the students. The contexts in question were the design process (within a studio) for the following products: 1) a three-dimensional (3D) textile toy based on small child's drawings, 2) a functional 
3D textile puzzle for visually impaired children and 3) wearable 3D textile sea creatures for Sea Life Helsinki. Finally, the implications for design education and the cultivation of students' design practices are presented.

\section{Learning by collaborative design}

Design artefacts, although concrete, represent a vast continuum of abstract and embodied ideas and meanings. In designing, conceptual and material aspects are simultaneously present: the participants develop their ideas and participate in knowledge-creating inquiries, as well as create design prototypes, material things and products. In these kinds of settings, the process and the object of designing emerge in collaboration; therefore the outcomes cannot be fully predicted - neither the order of the process phases nor the final artefact. In general, the complexity of the design process emerges from its cyclical and iterative nature, and thus, possible design solutions arise from a complex interaction between parallel refinement of the design problem and design ideas (Lahti, Seitamaa-Hakkarainen and Hakkarainen 2004). However, collaboration brings advantages as well as disadvantages. Collaborative designing is a process of actively communicating and working together to identify design constraints, create and share design ideas, deliberately make joint decisions, construct and modify developed design solutions, and produce shared design objects, as well as evaluate the outcomes through discourse (Hennessy and Murphy 1999, Lahti, SeitamaaHakkarainen and Hakkarainen 2004). In order to successfully address a design problem, a team must simultaneously deal with the design task and organize their process of working (Chiu 2002, Cross and Cross 1995, Lahti, Seitamaa-Hakkarainen and Hakkarainen 2004).

Designing is focused on creating and transforming design ideas into various material forms (Ramduny-Ellis et al. 2010). An important aspect of collaborative designing is working early on with shared design objects, such as visual representations, models, and concrete materials, e.g. models and mock-ups. Some students prefer to present ideas in visual ways by drawing, whereas other students like hands-on experimentation by creating and making tangible models that materialize their abstract ideas in concrete forms. In providing such a starting point, educators need to have skills and knowledge to support various formats of externalization and materialization in and for collaborative designing. They need to encourage students to just play with materials in order to provide new ways of working and managing the creative process. 
In the design studio model, design activities are organized for the pursuit of professional design tasks; there is, for example, a design brief that presents real-world design tasks. These tasks prompt students to experience the complexity of the entire design process: defining the design constraints, exploring and sketching design ideas, and experimenting with various materials. In our previous studies, we have systematically analysed collaboration in virtual design studios (SeitamaaHakkarainen, Lahti and Hakkarainen 2005), in different authentic collaborative design contexts, for instance, designing clothing for prematurely born babies (Lahti, Seitamaa-Hakkarainen and Hakkarainen 2004) or creating tactile books for visually impaired children (Lahti 2007). Conclusions from these previous studies highlight that the participants considered the solving of the authentic design task very important and motivating, and they designed inspiring and innovative products.

The pedagogical models that have been widely adopted in design education are experiential learning (Kolb 1984), reflective practice (Schön 1987), Learning by Design ${ }^{\mathrm{TM}}$ (Kolodner et al. 2003) and project-based learning (Greeno 2006, Scardamalia and Bereiter 2006). All these inquirybased pedagogical approaches emphasize the importance of engaging students in solving authentic and meaningful design challenges as well as learning by doing i.e. practice-based working. The LCD model (Seitamaa-Hakkarainen, Lahti and Hakkarainen 2005) provided the pedagogical framework for our previous studies. This model has its theoretical foundations in the pedagogical approaches of knowledge building (Bereiter and Scardamalia 2003; Scardamalia and Bereiter 2006) and constructionism (Kafai 2006).

The LCD model depicts the design process as spiral in nature; satisfactory design is approached iteratively through successive design cycles. The centre of the LCD model is distributed expertise and collaboration (see Figure 1). All participants work to develop the joint design object by sharing their expertise socially. The model emphasizes that collaboration should occur in all stages of the design process by creating shared design contexts, analysing design constraints, collecting and sharing new knowledge, prototyping and providing feedback on the artefacts being designed. The design process starts with participants performing a joint analysis of the design context. At this stage, the external constraints, design task and client have a critical role in determining the various physiological, emotional, psychological, social, and cultural aspects central to the process. During the framing of the design context, various, sometimes conflicting factors that affect the design process and define its requirements need to be considered. 


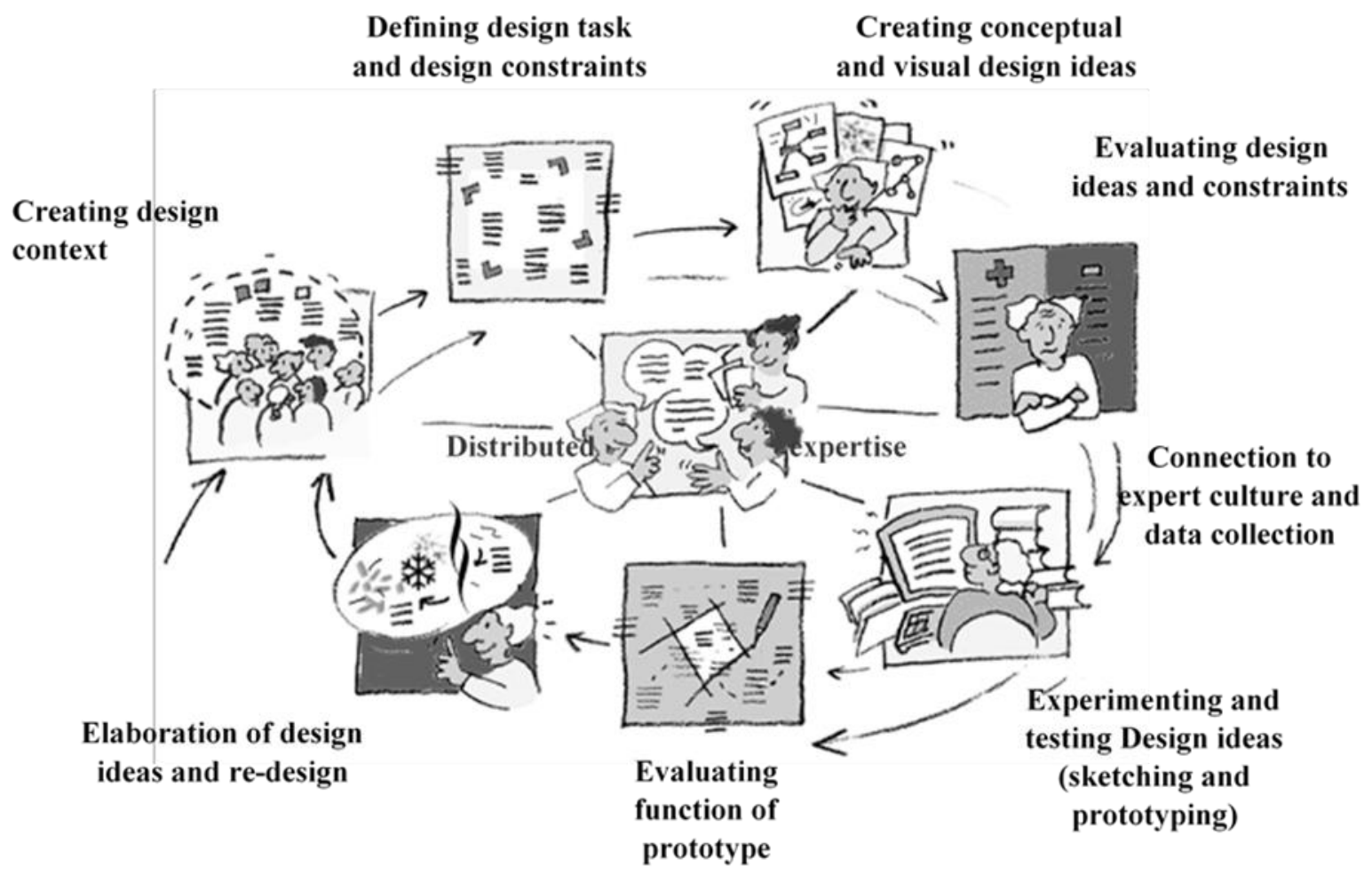

Figure 1. Learning by Collaborative Designing (LCD) model.

An essential aspect of the process is materialization of the ideas through visualizing or making and exploring design prototypes. By acquiring deepening knowledge, sharing that knowledge socially, producing varying design ideas and evaluating those ideas, the design process progresses cyclically. The efforts of the participants are organized towards developing shared, design ideas (conceptual artifacts), embodying and explicating those ideas in visual sketches (graphic artifacts or inscriptions), and giving the ideas a material form as prototypes or end results (e.g. fabricated products). From the beginning to the end, the design process is mediated by the shared artefacts being designed. Thus, constant cycles of idea generation and testing of design ideas by visual modeling or prototyping, characterize the process. Whereas in our previous design studio experiments, the LCD model provided a facilitating structure to students' virtual designing and collaboration, in this study, the model provided a pedagogical framework for collaborative designing when students are working side by side in the same space.

\section{Pedagogical infrastructures in the context of design learning}

It is important to provide sufficient structural support to facilitate novice students' collaborative design process and unleash the students' full potential during the complex design situation. In their 
analysis of how technology-enhanced collaborative knowledge creation is fostered, Lakkala and her colleagues (2008; Lakkala et al. 2010) identified interrelated technical, social, epistemic, and cognitive support structures. These structures are the building blocks of the framework of pedagogical infrastructure. The aim of the framework is to highlight, for educators, the essential underlying conditions that need to be designed and addressed in the learning environment to enhance desired collaborative knowledge-creation practices. The development of the framework was inspired by Bielaczyc (2006), who noted that when implementing knowledge-building pedagogy in schools, the central challenge lies in creating the appropriate social infrastructure around the technical one. She was referring to the classroom culture, its established norms, classroom practices and online activities involving the use of the technological environment (Bielaczyc 2006). Lakkala et al. (2008) defined the pedagogical infrastructure as conditions (activity, structures and artefacts) that were designed and implemented in an educational setting to support the desired type of learning. Pedagogical infrastructure can be seen as pedagogical scenarios, based on certain learning theories, as well as on descriptions of the organization of collaborative learning settings, sequences of learning activities and the nature of complex tasks i.e. who does what and when according to time, event and participant perspectives.

According to Lakkala et al. (2008), a technical infrastructure requires students to be provided with the suitable technological learning tools for supporting collaborative inquiry. A social infrastructure involves social arrangements (i.e. agreements and organizational structures) that invite the participants to collaborate and create a common ground. For a proper epistemological infrastructure, educators also need to encourage learners to treat knowledge as something that can be shared and jointly developed (Bereiter 2002, Scardamalia and Bereiter 2006). Creating new knowledge is seen to be a process embedded in shared practices ("knowledge practice") that are enacted (Hakkarainen 2009). Lastly, a productive cognitive infrastructure requires educators' efforts to facilitate the advancement of students' self-regulative competencies and meta-skills for monitoring collaborative aspects of learning processes. Cognitive infrastructure should provide concrete conceptual tools, such as guidelines, models, or templates, for supporting planning, monitoring and reflection. The distinction between epistemological and cognitive infrastructures is not, however clear-cut; the two are interrelated and prompt each other.

When talking about supporting a certain type of learning and related pedagogical infrastructures Lakkala et al. (2008) as well as Bielaczyc (2006) both refer to a knowledge-building framework or knowledge-creating learning. While 'knowledge building' highlights conceptual aspects of inquiry, it pays too little attention to the role of tools and other physically embodied aspects of inquiry 
(Hakkarainen 2009). Design projects, as presently considered, in contrast, engage the participants in pursuing in parallel both conceptual and material artifacts and iteratively transforming conceptual ideas in material forms in a way that, in turn, elicits further elaboration of ideas. In the following, we will depict the three design studio contexts, their structures, activities and the subsequent tasks, materials and tools given to the students.

\section{Data Collection: Context for Collaborative Design Settings}

This study is part of the multi-faceted Handling Mind: Embodiment, Creativity and Design research project funded by Academy of Finland. Out of the four research tracks involved, this study represents one focused on embodiment, materiality and collaboration in designing. The purpose of this track was to analyze design thinking in face-to-face studio-based practices and examine the ways of carrying out on-the-spot material experiments (drawing, models) during designing. The design task and organization for each session were carefully planned. Macro and micro level design processes of design teams were analysed from video recordings. The arrangement of video recording affected the practical ways of organizing the teams working. Two stationary cameras were used to trace selected teams' design processes from various perspectives (i.e. side view and view from above). During their face-to-face design sessions, the teams worked in several rooms. All materials produced (i.e. written notes, mind maps, sketches, mock-ups) were collected, and teams of students from 2013 and 2014 course were interviewed. For the present meta-analysis, we also included all design briefs, instructions for each session and all materials provided to students. Although some results of the video analysis of each of the three cases were published earlier (Lahti et al. 2016a, Lahti et al. 2016b, Härkki, Seitamaa-Hakkarainen and Hakkarainen 2016), the earlier studies did not analyse pedagogical infrastructures of the studio-based learning settings.

The data was collected in three consecutive years 2012-2014, from the course Basics of Craft and Design Studies. This course is a compulsory first-year course in a program for Craft Teacher Education, University of Helsinki, Finland. The 10-week course consists of lectures and team design sessions. The objective of the collaborative design task was for the participants to carry out an entire design project for the first time in their university studies. The theoretical lectures dealt with the nature of design problems, theories of design processes and the role of visualization.

During the lectures, the LCD model was introduced. The students met each other during the weekly two-hour lectures, followed by face-to-face teamwork sessions (2 hours). The predefined time schedule determined the arrangements (time, space and place) of the course. Immediately after this 
course, the students continued in the second course, Sewing Technology, where they made their designed products.

Approximately 34-38 textile teacher students participated in the course each year. For practical reasons, we invited each year 9-12 voluntary students (three to four teams) to participate in our research project. In the year 2012, only one design session was videotaped. That pilot study determined how we proceeded with data collection. Each year, the teams' work was organized as collaborative design sessions constructed around open-ended and authentic design tasks. Since this course is the first course for students entering into textile teacher education, the students neither knew each other very well nor had collaborated previously.

All teams got similar kinds of assignments, but the general theme of the design task was different each year. Each design task had special premises that needed to be considered while planning the courses, and thus the implementation of the courses varied slightly. Design tasks mainly focused on a 3D fabric product design, although in some cases, the textile surfaces were also created. The design assignment was divided into the subtasks that provided the framework of the design sessions: design constraints, visualization and building a mock-up model. Next, we presented the general structure of each case in Table 1, followed by a short overview of each of the design tasks.

Table1. Structure of design sessions and design tasks in each design studio.

\begin{tabular}{|c|c|c|c|}
\hline Session & $\begin{array}{l}\text { 3D Textile Toy } \\
(2012)\end{array}$ & $\begin{array}{l}\text { 3D Textile Puzzle } \\
\text { (2013) }\end{array}$ & $\begin{array}{l}\text { 3D Animal Accessory } \\
\text { (2014) }\end{array}$ \\
\hline Design brief & $\begin{array}{l}\text { Brief + Collect a } \\
\text { child's drawing }\end{array}$ & $\begin{array}{l}\text { Brief + Orientate to puzzles in the } \\
\text { websites: } \\
\text { http://www.gamesmuseum.uwaterloo.ca/Virt } \\
\text { ualExhibits/ puzzles/manipulative/index.html } \\
\text { http://www.leikkien.fi/epages/Kaupat.sf/fi_FI/? } \\
\text { ObjectPath=/Shops/leikkien/Products/S413A }\end{array}$ & $\begin{array}{l}\text { Brief }+ \\
\text { Visit SEA LIFE, } \\
\text { sketch and take } \\
\text { photos of sea animals }\end{array}$ \\
\hline $\begin{array}{c}\text { Design } \\
\text { constraints }\end{array}$ & Mind Map & $\begin{array}{l}10 \text { questions about the puzzle } \\
\text { Mind Map }\end{array}$ & Mind Map \\
\hline Visualization & Fabric collage & $\begin{array}{l}\text { Creative problem solving task } \\
\text { (Individual task) } \\
\text { Collaborative sketching task (Forms) }\end{array}$ & $\begin{array}{l}\text { Collaborative } \\
\text { sketching task }\end{array}$ \\
\hline Modeling & $\begin{array}{l}\text { Build a 3D mock-up } \\
\text { Pre-assigned } \\
\text { materials: } \\
\text { 1) pen \& paper } \\
\text { 2) modeling clay } \\
\text { 3) cardboard } \\
\text { 4) wire \& fiber } \\
\text { fabric }\end{array}$ & $\begin{array}{l}\text { Build a 3D mock-up } \\
\text { Pre-assigned materials: } \\
\text { 1) modeling clay } \\
\text { 2) cardboard and masking tape } \\
\text { 3) wire and fiber fabric }\end{array}$ & $\begin{array}{l}\text { Build a 3D mock-up } \\
\text { A free selection of } \\
\text { materials: } \\
\text { 1) cardboard } \\
\text { 2) masking tape } \\
\text { 3) wire } \\
\text { 4) fiber fabric } \\
\text { 5) net }\end{array}$ \\
\hline
\end{tabular}




\begin{tabular}{|l|l|l|l|}
\hline & Pattern of toy & & \\
\hline & & & Fabric collage \\
\hline Feedback & Presentation to peers & Presentation to peers & $\begin{array}{l}\text { Presentation to the } \\
\text { client }\end{array}$ \\
\hline
\end{tabular}

Three-Dimensional Textile Toys: Students received the design brief during the first lecture. They were asked to collect a drawing from a child and ask the child to explain what it represents (e.g. a monster, a fairy tale etc.) or, alternatively, to ask a child to draw a picture and tell the story behind it. In the first session, instructions for the making of a mind map and an additional source of inspiration, a booklet about making tactile books for visually impaired children, were given to the teams. In the second session, the teams made a fabric collage. For the building of a mock-up, each team received different materials 1) pen and paper, 2) masking tape and thin cardboard, or 3) wire and non-woven interfacing fabric. Later, most of the toys were donated to the children who made the drawings. Figure 2 presents one example of a two-year old girl's original drawing, mock-up model made by wire and non-woven interfacing fabric, prototype and final textile toy.

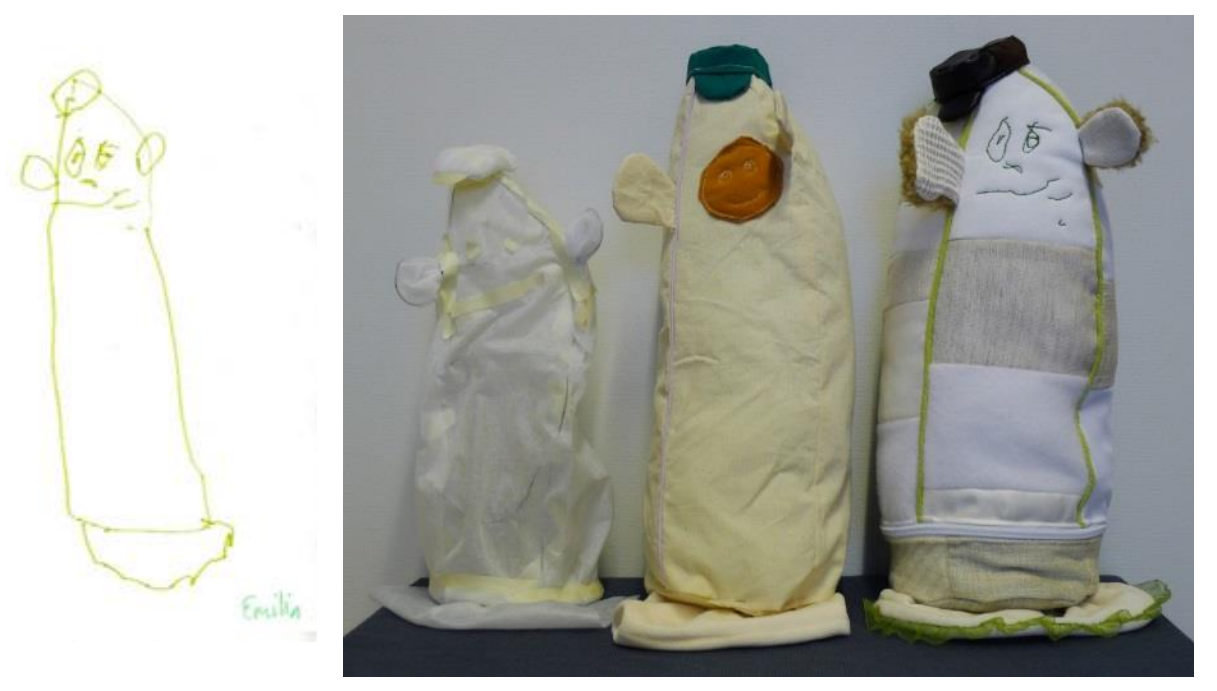

Figure 2. The drawing (left) by a child as a starting point; the mock-up model, the prototype and final product by Team Unto.

Three-Dimensional Textile Puzzles for visually impaired children; in the first session, the students received a booklet about tactile books, information about visual impairment and some web pages for orienting to 3D puzzles. Before the visualization session, each student individually completed one classical, creative problem-solving task, during which they randomly picked numbers that corresponded to shapes (e.g. cone, cube, rectangle etc.) and themes (for example, song, story and transportation). In the beginning of the visualization session, students were asked to negotiate and 
select which shapes and themes the team would be using. For building a mock-up the teams received similar materials as in the pilot experiment, only paper and pencil were excluded. The puzzles were donated to CELIA, a library for visually impaired people and those with other print disabilities. Figure 3 presents an example of the outcomes: a clay mock-up of the puzzles' pieces and the final 3D puzzle by one of the teams.

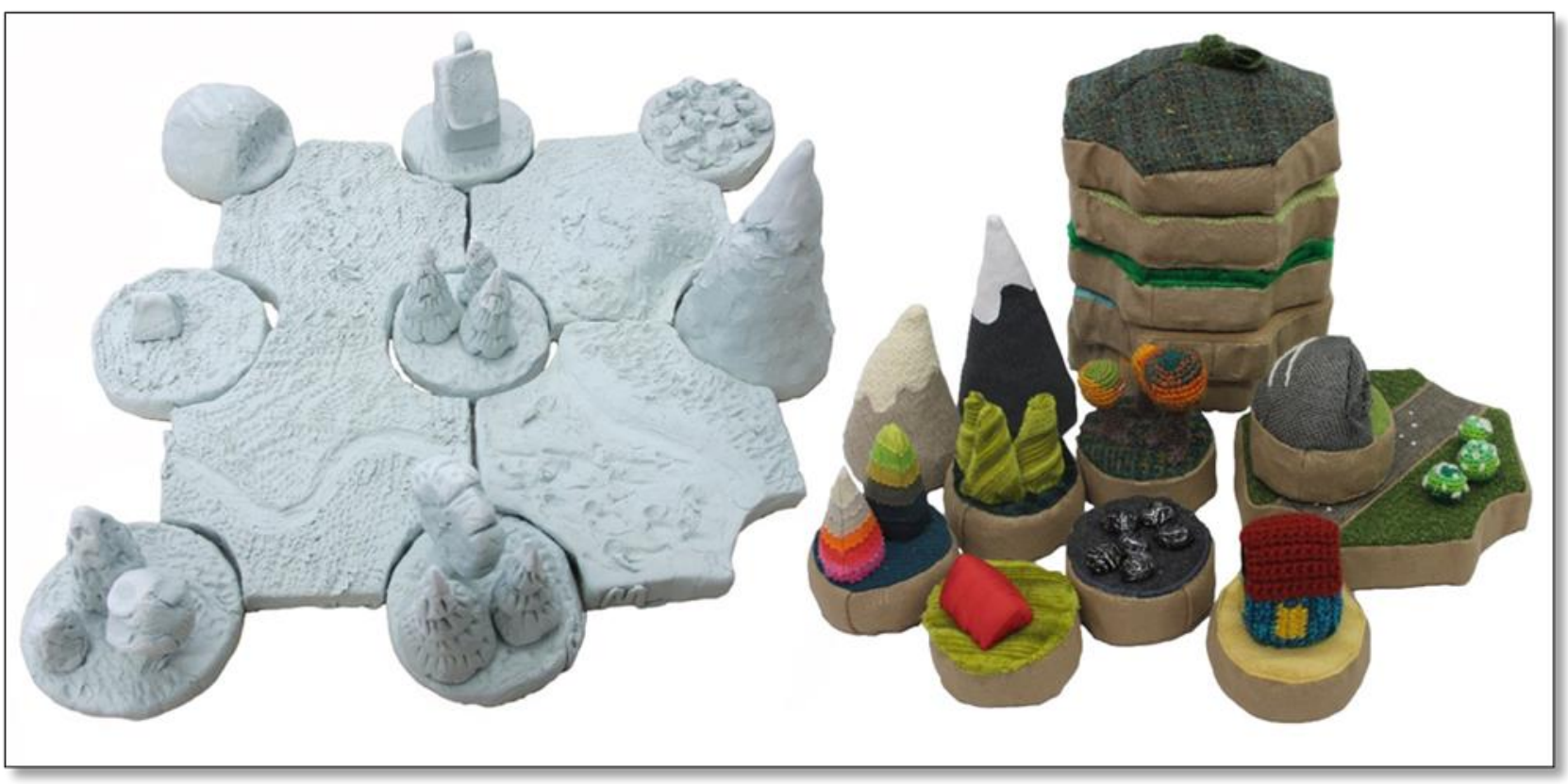

Figure 3. Pieces of Landscape Puzzle (clay mock up) and final product.

Wearable Textile Sea Creatures: This assignment took students to meet a client, SEALIFE Helsinki, who requested custom-made accessories, wearable sea creatures (replicas), for groups of visiting day-care children to use. The main structure of this experiment was slightly different due to the client's involvement. First, the teams engaged with the authentic environment in SEALIFE Helsinki with expert guidance about the world of sea creatures. Students were asked to collect sources of inspiration by sketching and taking photos with iPads. The next session focused on identifying design principles: final products should maximize use of recycled materials, feel authentic, be easy to dress and easy to maintain. The visualization session started with a lottery where each student received a name of a body part where the sea-creature accessories should be worn, and then the teams were asked to select one body part. In the mock-up session the teams were provided with a free choice of materials, as opposed to previous years where materials were preselected. After the mock-up session they were asked to make a fabric collage to represent their designs. The client twice provided feedback on design outcomes: after the mock-up and at end of the project when the creatures were donated to SEALIFE. Figure 4 presents an example of one team's effort. 

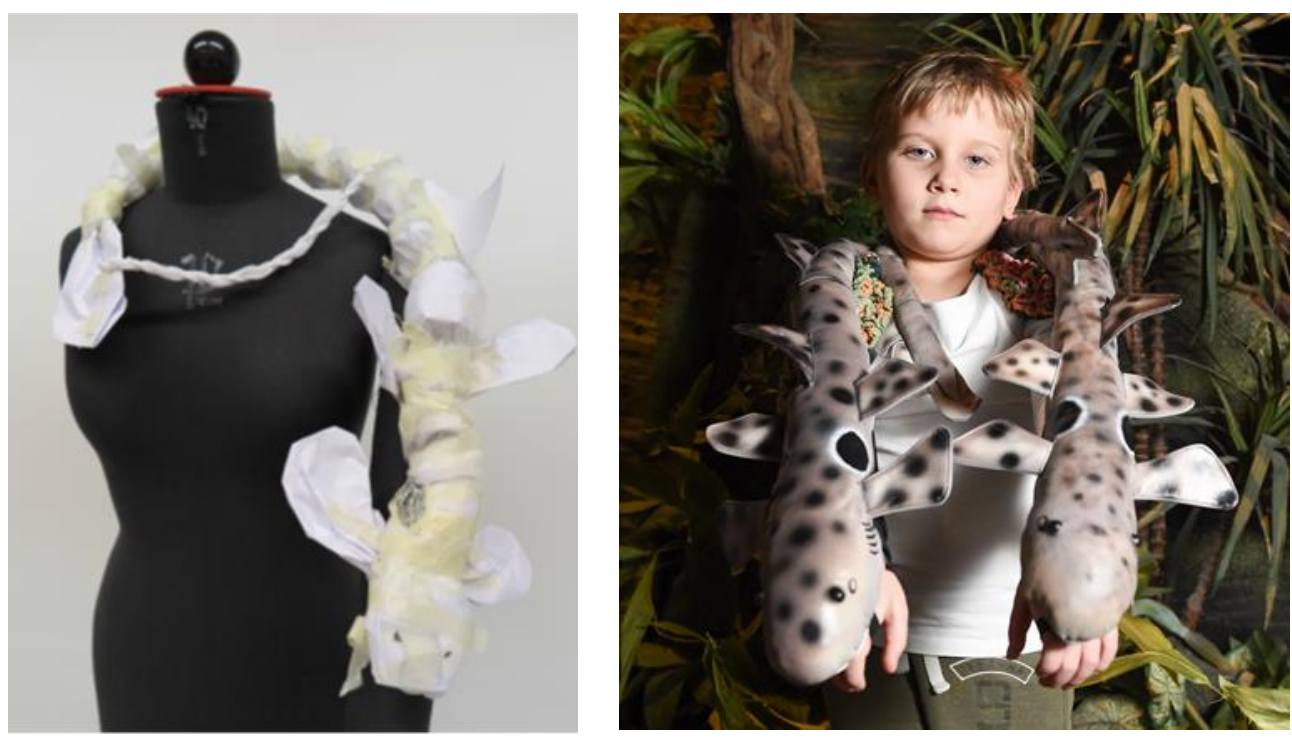

Figure 4. Mock up model of shark and final outcome of one team in the SEALIFE project.

\section{Method of data analysis}

We based our meta-level analysis on the design assignments, sub-tasks including scaffolds, practical arrangements of the design studios, the students' outcomes produced during the design sessions as well as the results documented in our previous articles (Lahti et al. 2016a, Lahti et al. 2016b, Härkki, Seitamaa-Hakkarainen and Hakkarainen 2016, Härkki, Hakkarainen and SeitamaaHakkarainen 2016). In addition, we utilized video recordings of the sessions and team interviews to provide examples of our results. Our analysis categories are based on pedagogical infrastructures (Lakkala et al. 2008; 2010) with some modifications. Table 2 presents components of pedagogical infrastructure, definitions and essential design features of our setting.

Table 2. Pedagogical infrastructure: components, definitions and essential features of the setting.

\begin{tabular}{|c|c|c|}
\hline Component & Definition & Essential features of the setting \\
\hline Technical & $\begin{array}{l}\text { Providing of technology and } \\
\text { technical advice to the participants } \\
\text { and organizing the use of } \\
\text { technology. } \\
\text { Functionality of the tools provided } \\
\text { and their appropriateness for the } \\
\text { desired activity. }\end{array}$ & $\begin{array}{l}\text { Techno-material tools and their } \\
\text { functionality: tools for designing, as } \\
\text { sources of inspiration, for refining and } \\
\text { further developing design ideas. } \\
\text { Appropriateness of the tools and } \\
\text { materials for the desired activity. }\end{array}$ \\
\hline Social & $\begin{array}{l}\text { Combination of designed } \\
\text { individual or collaborative } \\
\text { activities and outcomes. }\end{array}$ & $\begin{array}{l}\text { Shared process and object: the } \\
\text { collaborative learning activities and } \\
\text { outcomes. }\end{array}$ \\
\hline
\end{tabular}




\begin{tabular}{|c|c|c|}
\hline & $\begin{array}{l}\text { Arrangements to organize } \\
\text { students' collaboration and social } \\
\text { interaction. } \\
\text { Shared responsibility: tasks } \\
\text { defined in such way that the } \\
\text { accomplishment requires shared } \\
\text { responsibility. }\end{array}$ & $\begin{array}{l}\text { Physical and social arrangements to } \\
\text { organize social interaction. } \\
\text { Focused collaboration and joint team- } \\
\text { level objective: co-designing of } \\
\text { outcomes and joint orchestration of } \\
\text { everyone's contributions. }\end{array}$ \\
\hline Epistemological & $\begin{array}{l}\text { Ways of operating with } \\
\text { knowledge and the nature of } \\
\text { knowledge processing that the } \\
\text { assignments promote. } \\
\text { Concrete outcome: require that } \\
\text { inquiry includes the development } \\
\text { of concrete, tangible products as an } \\
\text { outcome of inquiry. }\end{array}$ & $\begin{array}{l}\text { Pedagogical principles: Learning by } \\
\text { Collaborative Design model (LCD). } \\
\text { Nature of knowledge and iterative } \\
\text { process: creating new knowledge and } \\
\text { working on design mode. Several } \\
\text { iterative evaluation and refinement of } \\
\text { ideas. } \\
\text { Making epistemological advancement } \\
\text { visible: externalize and publish their } \\
\text { latest advancements in designing. } \\
\text { Concrete outcome: sketches, a mock-up, } \\
\text { etc. concretized the epistemic } \\
\text { advancement. }\end{array}$ \\
\hline Cognitive & $\begin{array}{l}\text { Designed tasks and support } \\
\text { structures providing models that } \\
\text { promote students' competencies to } \\
\text { work in an intended way. } \\
\text { Nature of knowledge resources } \\
\text { used. } \\
\text { Provided cognitive models. }\end{array}$ & $\begin{array}{l}\text { Nature of design tasks: design brief and } \\
\text { sub-tasks, design constraints and order of } \\
\text { design sessions. } \\
\text { Cognitive scaffolds for designing: } \\
\text { session structure provided; templates, } \\
\text { guidelines relevant for professional } \\
\text { design, information sources. }\end{array}$ \\
\hline
\end{tabular}

\section{Results}

The notion of pedagogical infrastructures is a metaphor for emphasizing how design and implementation of collaborative learning settings is indirect, setting up background conditions that mediate the intended social and cultural practices but do not strictly prescribe learning activities (Lakkala et al. 2010). In the following text we will represent our results starting with the epistemological and cognitive infrastructures, because these components strongly informed the development of the courses. We continue to social and then technical infrastructures and provide some examples from the data to highlight our interpretations. 


\section{Epistemological infrastructure}

The epistemological infrastructure regarding pedagogical principles of LCD was apparent in all cases: design tasks were authentic and teams were solving complex, ill-defined design tasks through practices that explicitly and purposefully aimed at creating new design knowledge. Additionally, students were engaged in real design practices, in one case, interacting with a real client.

The LCD model implicitly emphasized reflective process. In all of the three design-studio cases, the given tasks and designed sessions guided students to iteratively assess and advance creative ideas becoming more refined: teams started by defining design constraints, then continued with ideation (idea generation and refinement) by working on subtasks. These involved iterative refinement of conceptual ideas as well as embodied activities: concrete working with materials for making mockups, prototypes and final products. The teams needed to externalize and share their design ideas and advancements in designing. In other words, epistemological advancement was made visible and audible and required several cycles of reflection and revision, cycles that sustained improvement of shared and concrete outcomes. Several teams noticed that design constraints and progressive characteristic of the sub-tasks facilitated designing and advanced the development of collaborative solutions. For example, one team described:

"The sub-tasks made it easier to advance our design. The second sub-task helped the most, even though we first felt that it slowed us down. It helped us to find the right track." (Landscape team, 2013)

The students acquired important experience of progressive design processes from the very beginning of their studies and they were able to create unique and practical design solutions for predefined tasks. In studio model learning, students faced challenges as part of guided problem-solving (i.e. a specific set of constraints that define how students can proceed): in particular, they needed to design solutions for authentic real-word problems while they were just learning about designing. Some teams focused more on defining the problem and using information that was related to the design brief and constraints; whereas some design teams focused more on generating solutions (Lahti et al. 2016b). In some cases, the student teams encountered some difficulties such as premature devotion to a design idea, which they needed to overcome. Anyhow, they were able to work independently, and they organized the available time efficiently. They gained confidence in their own ideas and developed abilities to communicate about them. Despite the complexity and the challenges, it would be worth the effort if the students learnt to implement progressive design processes in their future collaborative projects as textile teachers or designers. 


\section{Cognitive infrastructure}

The cognitive infrastructure was embedded in the design brief and sub-tasks that included the respective scaffolds assisted the intended actions. The structure of the learning setting, order of sessions and sub-tasks formed sequences for continued work in the entire design process. Further, each task required a tangible and concrete outcome (mind map, one or more sketches, a mock-up, a material collage, etc.) that concretized the advancement made by the teams. Regarding the teams' creative contexts two levels of epistemic criteria were set. First, the design briefs included ambitious objectives, external design constraints, and second, the teams themselves implicitly prioritized the external constraints and set internal constraints during designing. While the teams iterated their design solutions from task to task, they also reflected upon how their prioritized constraints were met. One team (Truck team 2013) explained the importance of authenticity provided by the design brief and constraints in following way:

Vanessa: To me, it would be nice, that it would be actually made somewhere, for something, for example we need to think why are we making it and for whom, at least personally that is what motivates me.

Pamela: So that you can be part of making something real.

Pamela: And so that it'd be fun and useful so that we could be proud of what we've done.

In each studio setting, when starting their first collaborative design session, students received some external knowledge sources (a CELIA booklet, internet links, guided visit of SEALIFE) but the ways and extent of their use were up to the teams. The design tasks in question included some guidelines - aspects the teams needed to consider. For example, to support the analysis of the design brief and constructing a mind map, some conceptual frameworks (e.g. Papanek model) were given to them. Additionally, the task of fabric collage invited teams to consider the importance of tactual senses, textural qualities and functional properties of materials (Härkki, Seitamaa-Hakkarainen and Hakkarainen 2016). In other words, teams participating in these design studios learned various conceptual tools and professional practices i.e. how professional designers work. The concepts of 'design constraints', 'representation', 'modeling', 'externalizing' and 'user needs' became part of their professional vocabulary. Designing was not always a smooth process, and some of the subtasks caused conflicts, contradiction and even fixation; new instructions forced teams to reconsider their previous initial ideas, to adopt or reject their ideas in order to find new creative ways to proceed. In the team interview, one team commented on the tasks and sub-task in the following way: 
Ann: We were slightly out of it after the first time [first session], like, yeah we're making this Landscape puzzle, and when we got the "form task" for the pieces as a starting point and we were like no, no .. but we realized that we can get a better idea and I don't know if we would have ended up like that. (Team Landscape 2013)

\section{Social infrastructure}

Social infrastructure is revealed in ways of forming the teams, organizing the physical working space and the task instructions emphasizing individual or collaborative work. Although the task instructions highlighted collaboration, the division of labor between team members was possible. In collaboration, idea exchange may both facilitate and hinder idea generation, which is partially dependent on the quality of interaction. Thus, appropriate social and physical settings facilitate participation and sharing of ideas, organize the design process, and support the emergence of a commitment to a common goal.

In our studio settings we started with fresh teams: the course starts at the beginning of the first term of textile teacher education; therefore, the students had no prior experience of working together. The teachers assigned volunteering students to teams. The joint team-level objective was also stated clearly: the design brief expressly indicated that each team should come up with one design. Furthermore, during design sessions, the teams were situated around a small table, worked in separate rooms and had no contact with outsiders - these physical and social arrangements also suggested that they should work in close collaboration. During video recording, an assistant operating a camera was present, but they did not participate in the teams' activities. However, the presence of video camera did create (more or less) a pressure for the teams to focus on the task at hand.

Focused collaboration was also supported by limiting all of the teams' design activities to prescheduled sessions that were part of the courses mentioned above. Each session was limited to two hours, a time also considered sufficient by the students. In the team interviews students told us that they did not discuss the task outside of the video recorded sessions, but they had thought about the task individually. From the video recordings we concluded that students concentrated on the task and there was not much off talk. Figure 5 illuminates the organized physical working space. The intent was to enable drawing on a shared piece of paper. Furthermore, Figure 5 shows how students shared their individual spaces by intensively explicating their ideas by pointing, producing figurative gestures or drawing, even on each other's papers. We have conducted micro-level analysis of students' gestures and sketching, the results of which also illustrated the importance of social and embodied interaction in focused collaboration (Härkki, Hakkarainen and Seitamaa- 
Hakkarainen 2016). Creativity builds on the social interaction and by externalization and materialization of the design ideas: the micro-level analysis revealed how creative ideas were proposed, shared and explicated to each other, and how these ideas were negotiated, redefined as well as rejected together. New ideas emerged from the visual clues of the drawings that triggered and helped develop ideas further. Correspondingly, experimenting with materials evoked new creative solutions.

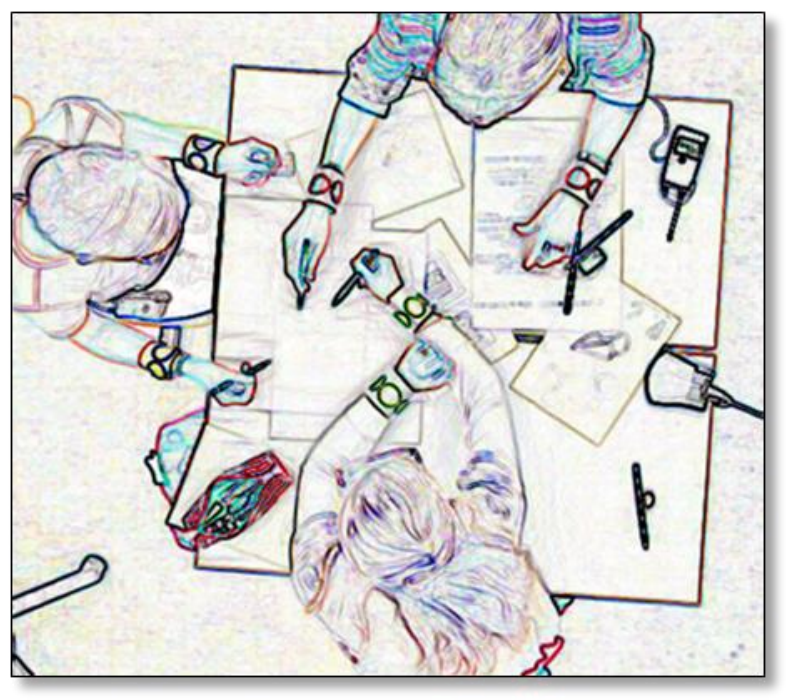

Figure 5. Social and physical arrangement of the session.

Since each sub-task and session highlighted different aspects of design activities, the teams, in general, followed the given instructions. However, even though the first session emphasized documenting design constraints into mind maps, many teams also proposed design ideas and solutions; the analysis of the design context also inspired ideation. In contrast, some teams followed instructions literally:

Vanessa: And then we followed the instructions quite literally.

Pamela: Quite literally to the letter, indeed.

Vanessa: Yeah, it instructed us quite a bit.

Pamela: Yeah, but on the other hand, it made it easier in that way.

Vanessa: Yeah.

Pamela: Kind of like we didn't have all the possibilities.

Vanessa: Hmm...

Pamela: Certain things which we could do...

Sara: Yeah, because it's apparently new for all of us, designing something like this, so if it's too expansive and if you don't have anything ... [instructions] is really missing... it can cause all kinds of pressure and anxiety.

We observed differences also in how teams organized their division of labour in different sessions. For example, with the 3D puzzle design task, one team created their mind map in two phases: first everyone individually listed important constraints, next they negotiated and organized their process 
to create their common mind map. Some teams emphasized the importance of mutual understanding more and accordingly encouraged each other, so that everyone's voice would be heard. However, the patterns of collaboration were affected by the mock-up task, typically teams divided the labour, i.e., each person was responsible for constructing certain parts of the artefact. Thus, besides social interaction, the task instructions, availability of materials and division of labour affects the nature of collaboration.

\section{Technical infrastructure}

Binder et al. (2011) argue that sufficiently rich material resources and design tools are crucial to support inspiration and social interaction in design teams. The material design artifacts, such as sketches, drawings, collages, cardboard, clay or foam models and physical prototypes, play a significant role in supporting collaboration between designers. External representations (graphical and physical) in various phases of the process provide diverse prompts to test design ideas. Thus, analyzing how the provided tools and materials actually supported or hindered production of representations is crucial.

In our design-studio learning settings the concrete tools and materials for defining, refining and further developing design ideas characterized the techno-material infrastructure. In different sessions (mind map, visualization, material collages, building mock-ups, making prototypes and final outcomes), teams worked with different tools and materials. The tools had a concrete nature: paper and pencil for mind maps and sketching, modeling clay or wire and non-woven interfacing fabric for building a model, and fabrics for material collages. All these tools and materials served certain functionality and relevance for the desired activity, in a particular design phase. Paper and pencil are ordinary tools for mind mapping and sketching, and they obviously supported those activities. However, the appropriateness of paper, pencil and sketching for designing was not selfevident due to lack of experience in sketching as a medium for quick ideation. In these three experiments, most of the sketches were rough, outline drawings confirming that some students were not used to drawing their ideas. The drawings were, however, understandable within the team, and they were annotated with crucial information. In the sea-creature project, students used iPads for photographing sea animals, sources of inspiration, and also for searching the internet for more information about sea animals. The other two projects could easily have utilized digital technologies similarly, to collect sources of inspiration. According to our observations, the amount and 
importance of sketching as a vehicle for idea development was less when digital technologies were available.

In two experiments (textile toy and sea creature), teams were asked to make a fabric collage in order to get directions for material selection. The teams were eager to make a fabric collage, especially in toy designing: collages concretized their vague ideas and added another layer of details, materials as colours and textures, even if the students anticipated that these materials would not be used for final products. In contrast, the collages for sea-creature designing, made at a later phase, presented preliminary ideas of actual material selection. In this project, students also manipulated and experimented the textile surfaces: they tried to imitate sea-creatures authentic surfaces by creatively applying colors, patterns and textile techniques.

The materials for building a mock-up provided interesting and varied results regarding the appropriateness of the tools. In the pilot experiment, textile toy design, all materials except the combination of paper and pencil supported the construction of the mock-up model. One team had only a pen and some paper for designing the 3D-shape of their toy, and they had obvious difficulties in transforming the child's two-dimensional (2D) drawing into a 3D object. The team was helpless and frustrated with the given materials. No other team experienced similar difficulties. Thus, we decided to exclude this modeling option from the proceeding courses.

Similarly, with the 3D textile puzzle, the teams worked with pre-assigned materials. Modeling clay was seen as a perfect material for substantiating ideas, and the team using it spent considerable time decorating their puzzle pieces. In later phases, they translated those details to textile surface structures. In the final interview, the team confessed that the detailed decorations were inspired by the nature of the modeling clay rather than their sketched design. On the other hand, one team criticized the idea of a mock-up; they insisted that understanding their somewhat complicated 3D structure and the planned detailed fastenings would have required a prototype made of fabric. This team encountered wire with opposing feelings: for one team member, it was the optimal modeling material, while another team member considered it the worst possible. The team that used cardboard and masking tape stated that cardboard was a good material since it guided them to omit unnecessary details that could have caused complications later in the sewing phase.

With the sea creature designs, the teams selected the materials they wanted to work with from cardboard, masking tape, wire, non-woven interfacing fabric and net. Due to the opportunity to select the materials, no material-related frustration occurred. In general, the teams discussed 
materials actively while sketching and making mind maps, but not as much when building mockups. They used figurative gestures actively to describe material properties. In Table 3, we characterize how the materials utilized for mock-ups supported various aspects relevant to design in two of the design courses.

Table 3. Mock-up materials supported various aspects.

\begin{tabular}{|c|c|c|c|c|c|c|c|c|}
\hline \multirow{2}{*}{$\begin{array}{c}\text { Materials as tools } \\
\text { to create... }\end{array}$} & \multicolumn{3}{|c|}{ 3D Puzzle (2013) } & \multicolumn{3}{|c|}{ Wearable Sea Creature (2014) } \\
\cline { 2 - 9 } & Team1 & Team2 & Team3 & Team4 & Team1 & Team2 & Team3 & Team4 \\
\hline $\begin{array}{c}\text { structure and } \\
\text { functionality }\end{array}$ & $\mathrm{X}$ & $\mathrm{X}$ & $\mathrm{X}$ & $\mathrm{X}$ & $\mathrm{X}$ & $\mathrm{X}$ & $\mathrm{X}$ & $\mathrm{X}$ \\
\hline visual & $\mathrm{X}$ & $\mathrm{X}$ & & $\mathrm{X}$ & $\mathrm{X}$ & $\mathrm{X}$ & & $\mathrm{X}$ \\
\hline tactile & & $\mathrm{X}$ & & & $\mathrm{X}$ & & $\mathrm{X}$ & \\
\hline auditory & & & & & & & & \\
\hline $\begin{array}{c}\text { expressive } \\
\text { meanings }\end{array}$ & & & $\mathrm{X}$ & $\mathrm{X}$ & $\mathrm{X}$ & & & \\
\hline
\end{tabular}

To conclude, materials and tools play an important role in designing. In design practice, materiality is more than a technical property of the materials. Different techno-material design tools need to adequately support designing in different phases. Interaction with materials is not only physical but spurs thinking as well. Working with different materials than the end product, helped students to construct 3D forms, test preliminary structural solutions and experiment with some details on the surface (for example with the clay). However, in some point of the textile design process it is important to start use and test these ideas with actual or similar kind of materials that will be used in the final product.

\section{Discussion}

The pedagogical approach of design studios is the traditional and widely used educational model. The central aim of studio-based working is to support a creative way of design thinking and knowledge creation. In the first instance, the studio method is used to provide students with individual experience of the entire design process. The design studio provides the socio-material working place, a classroom with materials and tools that are part of well-equipped workspaces or laboratories. The complexity of design tasks varies but always includes some sort of task instruction: open-ended tasks with some formal constraints. Some of these studios might offer expert lectures, field trips, pin-up sessions, critique sessions and teacher consultation during classwork time. They can include user participation and formal juries. The pedagogical basis 
focused on the nature of the design problem and learning by doing. The aim of the study was to provide a meta-analysis of three design-studio cases from the perspective of the epistemological, cognitive, social and technical infrastructures in the context of craft teacher education.

Due to the epistemological nature of designing, teams were engaged in creating iteratively refined, design artifacts and transforming those artifacts into various material forms towards increased specificity. The authentic design briefs, the structure of the learning setting and the order of the design sessions embodied the cognitive infrastructure. Additionally, each session pinpointed some of the professional methods (brainstorming of design constraints with mind maps, visualizing and materializing design ideas) that provided a scaffold (cf. Clark 1997, Wood et al. 1976) to designing. To support visualization, we created sub-tasks aimed at promoting the refinement of ideas instead of getting prematurely fixated on the first plausible idea. However, unanticipated and surprising as it was to us, these sub-tasks confused some students who sought a more specific level of interpretation for the task instructions; they wanted to know how literally or freely the instructions should be read. On the other hand, some teams simply adopted very liberal interpretations.

Social infrastructure involved working in teams across a series of intensive two-hour design sessions. These arrangements were partially due to our specific research interest related to materiality, embodiment and social interaction during students' working. All teams developed very workable and creative design solutions and produced their intended outcomes. The ways of assigning the teams and physical/spatial arrangements of working spaces facilitated participation in sharing of ideas and organizing the design process and supported the emergence of a commitment to joint team-level objectives.

The design studio is a physical place that consists of spaces, tools and materials arranged for the design students' convenience. The technical infrastructure in this study was based on concrete materials, tools and technologies provided for the teams. Learning in the design studio emphasizes simple but powerful creative thinking methods, such as sketching and modeling, which boost creativity and facilitate idea expression. As new ideas emerge the drawings form visual clues that trigger and help develop new images. Similarly, materialization of ideas evokes new ones.

Sketching outline drawings is usually considered an appropriate and important method to document design ideas quickly, though professional digital sketching tools have also been available for a long time. However, due to lack of support for quick rendering of ideas, they have not achieved widespread recognition among designers. Those digital design tools are more commonly used when 
ideas have received a certain level of specification (for example, Sketch Up, Thinkercad) and when designs must be presented to clients or other stakeholders. Nonetheless, introducing digital tools that support idea development is an area in which we see potential for improvement. IPads were only used in the sea- creature project to document sea animals. Use of Pinterest and Google for collecting sources of inspiration was a simple way to support teams' attempts to render creatures as authentic as possible. The main limitation of these design studio experiments was the narrow use of digital technology. The techno-material infrastructure will be addressed below in detail with a view to supporting novice textile teacher students' designing in the future.

In a traditional design studios, students produce paper prototypes and rough mock-ups. For the building of a mock-up, we provided various, commonly used materials to enable testing of design ideas with simple constructions. In general, materials helped teams to experiment with their ideas (size, shape, 3D construction); some materials helped more than others. However, the main design decisions were made during the ideation phase; in the later stages, no radically new ideas were proposed but there was materiality supported specification and refinement of ideas for various details. This was due to the teams' commitment to common solutions from early on, and also to the time restrictions. To summarize, various visual representations and materializations were created during the sessions, and teams achieved very original, functional and aesthetically pleasant end products that were donated to the end users or clients.

Our design studio constrained teams' collaboration by space and time arrangements. Although the design studio is a physical place (with the possibility to include virtual or blended learning) for designing, most importantly it is a process of learning to design. The important notion is tension between structure and flexibility within the design-studio setting, to best promote knowledge creation in a balanced way. The epistemic nature of activities (task-accomplishment cf. sharing of ideas) and the structuring of activities (rigid structures, scaffold-based inquiry) affect the degree of flexibility for the teams. When the aim is to implement collaborative work in creative areas in practice, we need to learn to tolerate openness yet, at the same time, provide sufficient structure. On the one hand, novice students need support and guidance to participate productively in creative collaborative processes; on the other hand, too much structure may undermine their own agency. We wish to emphasize that development of students' own agency during their education is critical.

Sawyer (2012) argued that knowledge creation is best thought of as an improvisational activity and that the best teaching is disciplined improvisation: teaching that provides flexible space required for learning, but guided within structures and frameworks - in a similar manner to professionally 
performed improvisations in many areas. We also argue that while designing is a creative activity; learning to design professionally requires learning the practices and methods that are the basis for creative working. It is evident that design educators should not control students' design thinking, but at the same time, the educators should have a clear vision of how each task is interpreted by the students and how the written instructions affect students' designing. This appeared to be a very critical point in the craft teacher students' designing but also in regard to design education in general. The emergent aspects of creative thinking need to be supported; however, especially we need to support focused creativity - too-open design tasks can cause a fall into familiar patterns or frustration in searching for conventional adequacy instead of creating new ideas (Sawyer 2012).

In the first years of the studies in Craft Teacher Education, design projects typically take about one or two months to complete. Later, these projects become progressively more open-ended and involve fewer constraints, longer periods of work, and a greater role for students' own preferences. The goal of project parameters or constraints is to limit students' creative options, so that their creative effort is focused on the specific learning outcomes that are desirable at that point in their learning trajectory (Saywer 2012). One of the strengths of our experiments was to initiate newcomers quickly to professional design tasks. The provided structures ensured that teams progressed at the same rhythm and went through all necessary phases - critical aspects of the process (e.g. sketching and material exploration). A weakness of the presented structures was that some teams committed to ideas quite early on in the project; prompts and scaffolds were not used productively to explore alternatives.

A question for the future is: how to better implement socio-digital tools in the learning environment, especially digital tools to support visualization and materialization? In a virtual design studio, introducing multiple tools for collecting sources of inspiration (such as Pinterest) or making digital mind maps (or virtual post-it notes) is not a challenge. When the internet can provide rich inspiration sources, it also might attract students to look for ready-made solutions, which limits their creativity.

Finding digital tools to support collaborative visualization and ideation is difficult. Current digital drawing systems may offer many benefits compared to traditional pen and paper sketching, even though efficient application of digital tools often requires some expertise. The available professional drawing tools are still quite expensive and do not support the need for rough sketches in the early stages of designing. However, for the iPad, some recently published, quite simple and inexpensive sketching applications exist. These applications used for quick drawings using fingers 
and touch, support the sharing of drawings within virtual learning environments. Productive use of many digital design tools requires advanced technical skills, a factor seriously limiting their use. Achieving technical expertise in digital designing requires extensive training. Further, many quite simple but special digital applications (for example CStitch, iWeaveIt and Knitting iCharts) that can be used to design certain kinds of surfaces, for example digital textile printing, embroidery stitches and knitting patterns exist nowadays. These digital applications are widely used in textile teacher education, but their applicability is restricted to detailed specifications of particular production techniques. They are domain-specific tools that do not facilitate ideation. However, they are quite easy to use and provide simple ways of experimentation in the later stage of textile designing.

Overall, the present investigation addressed various critical aspects of design learning in studio settings for craft teacher education. The pedagogic implementation of the three, studio cases involved deliberate structuring, necessary for providing sufficient support for novices and orienting them to participate in all critical aspects of designing, within the time limits. The epistemological, cognitive, social and techno-material infrastructures supported teams who succeeded in designing unique and creative textile based artefacts.

\section{References}

Bereiter, C. 2002. Education and mind in the knowledge age. New Jersey: Erlbaum

Bereiter, C. and Scardamalia, M. 2003. "Learning to work creatively with knowledge." In: E. de Corte, L. Verschaffel, N. Entwistle and J. van Merriënboer (Eds). Powerful learning environments. Unravelling basic components and dimensions, pp. 55-68. Oxford: Pergamon/Elsevier Science.

Bielaczyc, K. 2006. “Designing social infrastructure.” Journal of the Learning Sciences 15(3): 301329.

Binder, T., De Michelis, G., Ehn, P., Jacucci, G., Linde, P. and Wagner, I. 2011. Design things. Cambridge, MA: MIT Press.

Clark, A. 1997. Being there: Putting brain, body and world together again. Cambridge, MA: MIT.

Chamorro-Koc, M., Scott, A. and Coombs, G. 2015. "Bombs Away: Visual thinking and students' engagement in design studios contexts." Design and Technology Education: An International Journal 20(1): 18-28.

Chiu, M-L. 2002. "An organizational view of design communication in design collaboration." Design Studies 23(2): 187-210. 
Cross, N. and Cross, A. 1995. "Observations of teamwork and social processes in design." Design Studies 16(2): 143-170.

Goldschmidt, G, Hochman, H., and Dafni, I. 2010. "The design studio "crit": Teacher-student communication." Artificial Intelligence for Engineering Design, Analysis and Manufacturing 24: $285-302$.

Greeno, J. G. 2006. "Learning in activity." In R. K. Sawyer (Ed.) The Cambridge handbook of the learning sciences, pp. 79-96. New York: Cambridge University Press.

Hakkarainen, K. 2009. "A knowledge-practice perspective on technology-mediated learning." International Journal of Computer Supported Collaborative Learning 4: 213-231.

Härkki, T, Hakkarainen, K and Seitamaa-Hakkarainen, P. 2016 (online first). "Line by line, part by part - collaborative sketching for designing." International Journal of Technology and Design Education.

Härkki, T., Seitamaa-Hakkarainen, P. and Hakkarainen, K (2016). "Material knowledge in collaborative designing and making. A case of wearable sea creatures." FORMakademisk, 9:1, Art 5: $1-21$.

Hennessy, S. and Murphy, P. 1999. "The potential for collaborative problem solving in design and technology." International Journal of Technology and Design Education 9(1): 1-36.

Kafai, Y.B. 2006. “Constructionism.” In: R. K. Sawyer (Ed) The Cambridge handbook of the learning sciences, pp 35-46. New York: Cambridge University Press.

Kolb, D. 1984. Experiential Learning. Englewood Cliffs, NJ: Prentice-Hall.

Kolodner, J.L., Camp, P.J., Crismond, D., Fasse, B., Gray, J., Holbrook, J. and Ryan, M. 2003. "Problem-based learning meets case-based reasoning in the middle school science classroom: Putting Learning by Design ${ }^{\mathrm{TM}}$ into practice." Journal of the Learning Sciences 12(4): 495-547.

Laamanen, T-K. and Seitamaa-Hakkarainen, P. 2014. "Constraining an open-ended design task by interpreting sources of inspiration." Art, Design and Communication in Higher Education 13(2): 135-156.

Lahti, H. 2007. "Collaboration between students and experts in a virtual design studio." Journal of Design Research 6(4): 403-421.

Lahti, H., Kangas, K., Koponen, V. and Seitamaa-Hakkarainen, P. 2016a. "Material mediation and embodied actions in collaborative design process." Techne Series A 23(1): 15-29.

Lahti, H., Seitamaa-Hakkarainen, P. and Hakkarainen, K. 2004. "Collaboration patterns in computer-supported collaborative designing.” Design Studies 25(4): 351-371.

Lahti, H., Seitamaa-Hakkarainen, P., Kangas, K., Härkki, T. and Hakkarainen, K. 2016b. "Textile teacher students' collaborative design processes in a design studio setting." Art, Design and Communication in Higher Education 15(1): 35-54. 
Lakkala, M., Ilomäki, L. and Kosonen, K. 2010. "From instructional design to setting up pedagogical infrastructures." In B. Ertl (ed.) Technologies and Practices for Constructing Knowledge in Online Environments, pp. 169-185. Hershey, PA: Information Science Reference,.

Lakkala, M., Muukkonen, H., Paavola, S. and Hakkarainen, K. 2008. Designing pedagogical infrastructures in university courses for technology-enchanced collaborative inquiry. Research and Practice in Technology Enhanced Learning, 3:1, 33-64

Lee, N. 2009. "Project methods as the vehicle for learning in undergraduate design education." Design Studies 30(5): 541-560.

Paavola, S. and Hakkarainen, K. 2014. "Trialogical approach for knowledge creation." In S-C. Tan, H-J. Jo, and J. Yoe (Eds.) Knowledge creation in education, pp. 53-72. Education Innovation Series.Singapore: Springer.

Ramduny-Ellis, D., Dix, A., Evans, M., Hare, J. and Gill, S. 2010. "Physicality in design." The Design Journal 13(1): 48-76.

Sawyer, K. 2012. "Learning how to create." In J. van Aalst, K. Thompson, M. J. Jacobson and P. Reimann (eds.) The future of learning: Proceedings of the 10th International Conference of the Learning Sciences (ICLS 2012), full papers, (1), pp. 33-36. Sydney: International Society of the Learning Sciences.

Scardamalia, M., and Bereiter, C. 2006. "Knowledge building." In R. K. Sawyer (Ed.) The Cambridge handbook of the learning sciences, pp. 97-115. Cambridge: Cambridge University Press.

Schön, D. (1987). Educating the Reflective Practitioner. San Francisco: Jossey-Bass.

Seitamaa-Hakkarainen, P. and Hakkarainen, K. 2001. 'Composition and construction in experts' and novices’ weaving design.” Design Studies 22(1): 47-66.

Seitamaa-Hakkarainen, P., Lahti, H. and Hakkarainen, K. (2005) "Three Design Experiments for Computer Supported Collaborative Design." Art, Design and Communication in Higher Education 4(2): 101-119.

Wood, D., Bruner, J. and Ross, G. (1976). "The role of tutoring in problem solving." Journal of Child Psychology and Psychiatry and Allied Disciplines 17: 89-100. 